Revista Brasileira de

Engenharia Agrícola e Ambiental

v.15, n.10, p.1062-1067, 2011

Campina Grande, PB, UAEA/UFCG - http://www.agriambi.com.br

agriambi Protocolo 239.10 - 28/12/2010 • Aprovado em 09/08/2011

\title{
Influência da escala na análise morfométrica de microbacias hidrográficas
}

\author{
Marcelo Zanata ${ }^{1}$, Teresa C. T. Pissarra ${ }^{2}$, Christiano L. Arraes ${ }^{3}$, \\ Flavia M. Rodrigues ${ }^{1} \&$ Sérgio Campos $^{4}$
}

\begin{abstract}
RESU M 0
No intuito de verificar a influência da escala na análise física de bacias hidrográficas utilizou-se o método da análise morfométrica visando aos dados quantitativos e, com isto, diferenciar áreas homogêneas dentro desta unidade territorial. Entre as variáveis estudadas estão as dimensionais, as do padrão de drenagem e as do relevo. A área de estudo é a microbacia hidrográfica do Córrego da Cachoeira. As bases cartográficas na escala 1:50000 (IBGE) e 1:10000 (IGC) foram utilizadas para a hierarquização da rede de drenagem e para a análise morfométrica. A microbacia se caracteriza por se tratar de uma drenagem fluvial exorreica, com rios consequentes e drenagem dendrítica. 0 baixo valor do fator de forma indica uma bacia mais alongada e com menor risco de enchentes sazonais. Os valores de densidade de drenagem, frequência de rios e razão de bifurcação, são considerados baixos e indicam a formação de solo sobre rocha permeável. Os baixos valores para a razão de relevo e a razão de relevo relativo, sugerem uma microbacia com relevo relativamente suave. 0 detalhamento da cartografia com a referência terrestre revelou maior número de compartimentos hidrológicos e aumentou o comprimento da rede de drenagem refletindo, assim, em alterações sutis nos resultados obtidos para as variáveis físicas analisadas.
\end{abstract}

Palavras-chave: morfometria, padrão de drenagem, cartografia oficial

\section{Scale influence in morphometric analysis of the watersheds}

\begin{abstract}
A B STRACT
In order to verify the different scales in physical analysis of watersheds, the geomorphic quantitative analysis was done to distinguish homogeneous areas within this land unit. The variables studied were the dimensions, drainage pattern and relief characteristics. The study area is the watershed of the Córrego da Cachoeira, São Paulo State, Brazil. The cartographic scale 1:50000 (IBGE) and 1:10000 (IGC) were used to delineate the drainage network and study the morphometric characteristics. The watershed is characterized as an exoreic, fluvial drainage with consequent streams and drainage pattern. The values of the drainage density, frequency of rivers and the ratio of bifurcation are considered low, indicating the formation of the soil on permeable rock. The low values suggested a watershed with relatively mild relief. The detail of the cartography mapping analysed with field study data show ed higher values of hydrological compartments and length of the drainage network, reflecting changes in the results obtained on the physical variables analysed.
\end{abstract}

Key words: morphometry, drainage pattern, official mapping

\footnotetext{
${ }^{1}$ D outorandos, DER/U N ESP, Campus de Jaboticabal, Rodovia Cândido Portinari, km 347, C.P. 68, CEP 14300-000, Batatais, SP. Fone (16) $3662-6327$. Email: marcel_zanata@netsite.com.br; flamazzer@hotmail.com

2 D ER/U N ESP, Campus de Jaboticabal, Via de Acesso Prof. Paulo D onato Castellane, s/n, CEP 14884-900, Jaboticabal, SP. Fone (16) $3209-2637$. Email: teresap@fcav.unesp.br

3 D outorando, FEAG RI/U NICAMP, Rua Cândido Rondon 501, CEP 13083-875, Campinas, SP. Fone (16) 8134-4080. Email: christianoarraes@yahoo.com.br ${ }^{4}$ DER/U N ESP, Fazenda Lageado, C.P. 237, CEP 18610-307, Botucatu, SP. Fone: (14) 3811-7100. Email: seca@fca.unesp.br
} 


\section{INTRODUÇÃO}

A verificação da referência terrestre é muito usada na elaboração de mapa de degradação ambiental (Candido et al., 2010; Lima Neto et al., 2008), para confirmar as informações obtidas pelas técnicas de sensoriamento remoto e sistemas de informações geográficas (Reis et al., 2008) e estabelecer a escala de trabalho, ou seja, a relação entre a medida de uma porção territorial representada no papel e sua medida real na superfície terrestre. Assim, a partir de dados cartográficos pode-se representar o relevo da superfície terrestre, que é o resultado da interação entre processos tectônicos, pedogênicos e intempéricos, que atuam de forma diversificada nos diferentes materiais rochosos.

No início do século XX os estudos de Horton (1945) e Strahler (1957) definem a hierarquia fluvial, considerando as nascentes e seus cursos d'água, sendo que os canais sem tributários são os de primeira ordem, os de segunda ordem são formados por canais de primeira, e assim, sucessivamente.

A morfometria da microbacia hidrográfica é ferramenta essencial de diagnóstico da suscetibilidade à degradação ambiental. Retrata a disposição, o tamanho e a forma do percurso de cada segmento de rio e a densidade e o modo de distribuição de toda a rede de drenagem do terreno (Strahler, 1957; França, 1968).

A água constitui-se no principal fator de desenvolvimento e preservação dos seres vivos. Atualmente, as bacias hidrográficas subsidiam grande parte da legislação e do planejamento territorial e ambiental brasileiro (Politano \& Pissarra, 2003). De acordo com Tonello et al. (2006), as características físicas e bióticas de uma bacia exercem papel significativo nos processos do ciclo hidrológico influenciando, dentre outros, a infiltração, a quantidade de água produzida como deflúvio, a evapotranspiração e o escoamento superficial e subsuperficial.

De maneira geral, a obtenção de dados quantitativos das microbacias hidrográficas é realizada na escala 1:50000 (Rodrigues \& Carvalho, 2009; Cardoso et al., 2006; Reis et al., 2008) ou com sistemas de informações geográficas e imagens de satélite (Silva et al., 2007; Torres et al., 2007; Candido et al., 2010; Oliveira et al., 2010; Arraes et al., 2010a; Arraes et al., 2010b). O trabalho com escalas maiores (1:10000) raramente é utilizado (Teodoro et al., 2007) e a confirmação em campo se torna dependente da área de estudo perdendo, assim, a referência terrestre das informações cartográficas.

O presente trabalho tem por objetivo calcular e analisar as características dimensionais, do padrão da rede de drenagem e do relevo da microbacia hidrográfica do Córrego da Cachoeira, Município de Batatais, SP, com as diferentes escalas das bases cartográficas oficiais (1:50000, 1:10000) e com a constatação da referência terrestre, para verificar a influência da escala na análise morfométrica de microbacias hidrográficas.

\section{Material e MÉTOdos}

A microbacia hidrográfica do Córrego da Cachoeira está situada entre as coordenadas geográficas $20^{\circ} 53$ ' $35^{\prime \prime}$ a $20^{\circ} 57^{\prime}$
54" de Latitude S e 47 31' 45" a 47 33' 21" de Longitude W Gr. Segundo Köppen, o clima é classificado mesotérmico úmido de verão quente (Cwa), com temperatura média do mês mais quente superior a $22^{\circ} \mathrm{C}$ e a média do mês mais frio inferior a $18^{\circ} \mathrm{C}$. A precipitação média anual varia entre $1.100 \mathrm{e} 1.700 \mathrm{~mm}$.

As rochas efusivas básicas da Formação Serra Geral (basalto) e as areias não consolidadas de origem mais recente (arenitos), provavelmente do cenozóico, recobrem as rochas efusivas básicas da área (São Paulo, 1981). Segundo o Sistema Brasileiro de Classificação de Solos (Camargo \& Kaufmann, 1987), esses são classificados como Latossolo VermelhoAmarelo, textura média.

Para a análise morfométrica foram usadas as bases cartográficas do Instituto Brasileiro de Geografia e Estatística (IBGE), folha SF-23-V-A-IV-4 na Escala 1:50000 (Brasil, 1971) e do Instituto Geográfico e Cartográfico (IGC), Escala 1:10000 (São Paulo, 1992), folhas Capão Grande, Batatais, Fazenda Esteio, Ribeirão da Mata, Córrego da Prata, Chácara Caiapós, Brodowski e Córrego Olhos D’água.

$\mathrm{Na}$ vetorização dos dados referentes à conformação geomorfológica da rede de drenagem e respectivas sub-bacias de $1^{\mathrm{a}}, 2^{\mathrm{a}}, 3^{\mathrm{a}}$ e $4^{\mathrm{a}}$ ordens, utilizou-se o pacote computacional AutoCADMap 2008, gerando um banco de dados com as medidas das características dimensionais, do padrão de drenagem e do relevo, com metodologias utilizadas por Arraes et al. (2010a), Rodrigues et al. (2008), Teodoro et al. (2007) e Pissarra et al. (2004). A Tabela 1 mostra as variáveis calculadas no presente trabalho, com as respectivas metodologias.

A classificação da rede de drenagem e as microbacias hidrográficas foram hierarquizadas nas diferentes escalas, de acordo com o sistema de Horton (1945), modificado posteriormente por Strahler (1957), em que os canais sem tributários são os de $1^{\mathrm{a}}$ ordem, os de $2^{\mathrm{a}}$ ordem são formados por canais de $1^{\mathrm{a}}$, e assim sucessivamente.

Para cada base cartográfica e para a referência terrestre houve a reclassificação das hierarquias fluviais. As características físicas foram analisadas para as diferentes escalas e para a referência terrestre.

\section{RESUlTADOS E DisCUSSÃO}

Segundo Christofoletti (1974) a área de estudo se caracteriza por ser uma drenagem fluvial contínua até o oceano (exorreica), formando cursos d'água que coincidem com a inclinação principal das camadas rochosas (consequentes), assemelhando-se à configuração de uma árvore, denominada dendrítica.

Considerando a base cartográfica do IBGE (Figura 1) e segundo Horton (1945), modificado por Strahler (1957), a área de estudo é classificada como microbacia de $4^{\mathrm{a}}$ ordem, contendo 2 microbacias de $3^{\mathrm{a}}$ ordem, 5 microbacias de $2^{\mathrm{a}}$ ordem e 18 microbacias de $1^{\mathrm{a}}$ ordem, totalizando 26 compartimentos hidrológicos (Pissarra, 2009). Quando da constatação em campo das informações cartográficas a referência terrestre mostra o desaparecimento da nascente 15 da Figura 1.

Considerando a base cartográfica do IGC (Figura 2), a área de estudo permanece com a mesma hierarquia fluvial da escala 1:50000 (Figura 1). A planta original apresenta o total de 17 
Tabela 1. Características morfométricas dimensionais do padrão de drenagem e do relevo, fórmulas e fontes das variáveis em estudo na microbacia do Córrego da Cachoeira, Batatais, SP

\begin{tabular}{|c|c|c|c|}
\hline Variáveis & Descrição & Fórmula & Fonte \\
\hline $\begin{array}{c}\text { Área }(A) \\
\text { Perímetro }(P)\end{array}$ & $\begin{array}{l}\qquad A \text { - Dimensional } \\
\text { Superfície total da bacia A }\left(\mathrm{Km}^{2}\right) \\
\text { Comprimento divisor topográfico } \mathrm{P}(\mathrm{Km})\end{array}$ & & $\begin{array}{l}\text { Horton (1945) } \\
\text { Smith (1950) }\end{array}$ \\
\hline$>$ comprimento $(\mathrm{C})$ & $\begin{array}{l}\text { Linha reta sobre o vale principal que une a foz ao } \\
\text { ponto extremo do divisor } C(\mathrm{Km})\end{array}$ & & Schumm (1956) \\
\hline$>$ largura $(\mathrm{L})$ & $\begin{array}{l}\text { Maior dimensão linear num eixo transversal ao vale } \\
\text { formado } L(\mathrm{Km})\end{array}$ & & Strahler (1958) \\
\hline $\begin{array}{l}\text { Comprimento da rede de } \\
\text { drenagem }(\mathrm{Cr})\end{array}$ & $\begin{array}{l}\text { Comprimento total dos seguimentos de rios que } \\
\text { formam as microbacias } \mathrm{Cr}(\mathrm{km})\end{array}$ & & Horton (1945) \\
\hline Fator de forma (Ff) & $\begin{array}{l}\text { Razão entre a área da bacia e um retângulo ( } \mathrm{L} \\
\text { média, C axial da bacia) }\end{array}$ & $\mathrm{Ff}=\mathrm{A} / \mathrm{C}^{2}$ & $\begin{array}{l}\text { Horton (1945) } \\
\text { Torres et al. (2007) }\end{array}$ \\
\hline $\begin{array}{l}\text { Coeficiente de compacidade } \\
\text { (KC) }\end{array}$ & $\begin{array}{l}\text { Relação entre perímetro e circulo de área igual a da } \\
\text { bacia ( }=1,>\text { enchente) }\end{array}$ & $\mathrm{Kc}=0,28 *\left(\mathrm{P} / \mathrm{A}^{1 / 2}\right)$ & $\begin{array}{l}\text { Oliveira et al. (2010) } \\
\text { Torres et al. (2007) }\end{array}$ \\
\hline Índice de circularidade (IC) & $\begin{array}{l}\text { Tende para a unidade na forma circular, diminui ao } \\
\text { alongar }\end{array}$ & $\mathrm{IC}=(12,57 * \mathrm{~A}) / \mathrm{P}^{2}$ & $\begin{array}{l}\text { Oliveira et al. (2010) } \\
\text { Torres et al. (2007) }\end{array}$ \\
\hline \multicolumn{4}{|c|}{ B - Padrão de drenagem } \\
\hline Densidade de drenagem (Dd) & $\begin{array}{l}\text { Relação entre comprimento da rede de drenagem } \\
(\mathrm{Cr}) \text { e área da bacia }(\mathrm{A})\left(\mathrm{Km} \mathrm{Km}^{-2}\right)\end{array}$ & $\mathrm{Dd}=\mathrm{Cr} / \mathrm{A}$ & Horton (1945) \\
\hline Freqüência de rios (F) & $\begin{array}{l}\text { Relação entre número de segmentos de rios (Nt) e } \\
\left.\text { área da bacia (A) (Nt Km}{ }^{-2}\right)\end{array}$ & $\mathrm{F}=\mathrm{Nt} / \mathrm{A}$ & Horton (1945) \\
\hline Razão de textura (T) & $\begin{array}{l}\text { Razão entre número de segmentos de rios }(\mathrm{Nt}) \text { e } \\
\text { perímetro da bacia }(\mathrm{P})\left(\mathrm{Nt} \mathrm{Km} \mathrm{Km}^{-1}\right)\end{array}$ & $\mathrm{T}=\mathrm{Nt} / \mathrm{P}$ & $\begin{array}{l}\text { França (1968) } \\
\text { Smith (1950) }\end{array}$ \\
\hline $\begin{array}{l}\text { Extensão de percurso superficial } \\
\text { (Eps) }\end{array}$ & Função da densidade de drenagem (Km) & $E p s=1 /(2 * D d)$ & Horton (1945) \\
\hline $\begin{array}{l}\text { Coeficiente de manutenção } \\
(\mathrm{Cm})\end{array}$ & Função da densidade de drenagem $\left(\mathrm{m}^{2}\right)$ & $\mathrm{Cm}=(1 / \mathrm{Dd}) * 1000$ & Schumm (1956) \\
\hline Razão de bifurcação & $\begin{array}{c}\text { Relação entre o } n^{0} \text { de segmentos de uma ordem e a } \\
\text { imediatamente superior }\end{array}$ & $\mathrm{Rb}=\mathrm{N} / \mathrm{N}+1$ & Horton (1945) \\
\hline \multicolumn{4}{|c|}{ C - Relevo } \\
\hline Amplitude altimétrica $(\mathrm{H})$ & Diferença entre maior cota e sua foz (m) & $\mathrm{H}$ & Strahler (1952) \\
\hline Razão de relevo (Rr) & $\begin{array}{l}\text { Relação entre a amplitude altimétrica e o maior } \\
\text { comprimento da bacia }\left(\mathrm{m} \mathrm{m}^{-1}\right)\end{array}$ & $\mathrm{Rr}=\mathrm{H} / \mathrm{C}$ & Schumm (1956) \\
\hline Razão de relevo relativo ( $\mathrm{Rrl}$ ) & $\begin{array}{l}\text { Relação entre a amplitude altimétrica e o perímetro } \\
\text { da bacia }\left(\mathrm{m} \mathrm{m}^{-1}\right)\end{array}$ & $\mathrm{Rrl}=\mathrm{H} / \mathrm{P}$ & Strahler (1958) \\
\hline
\end{tabular}

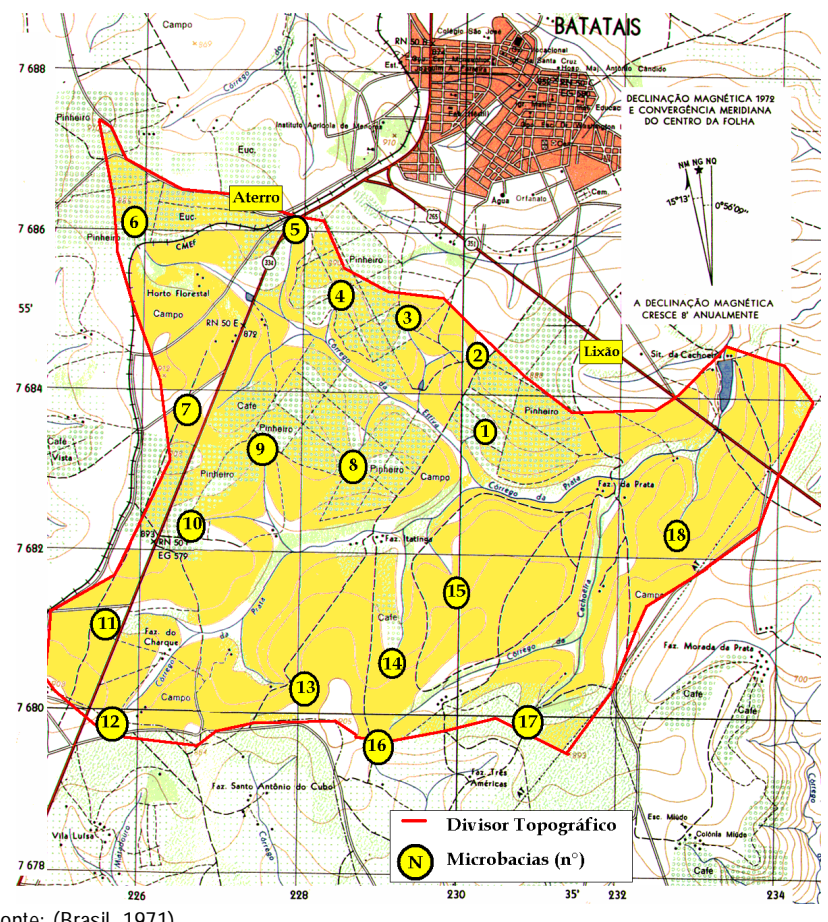

Fonte: (Brasil, 1971)

Figura 1. Microbacias avaliadas na Carta do Brasil - Instituto Brasileiro de G eografia e Estatística (IBGE), Escala 1:50000

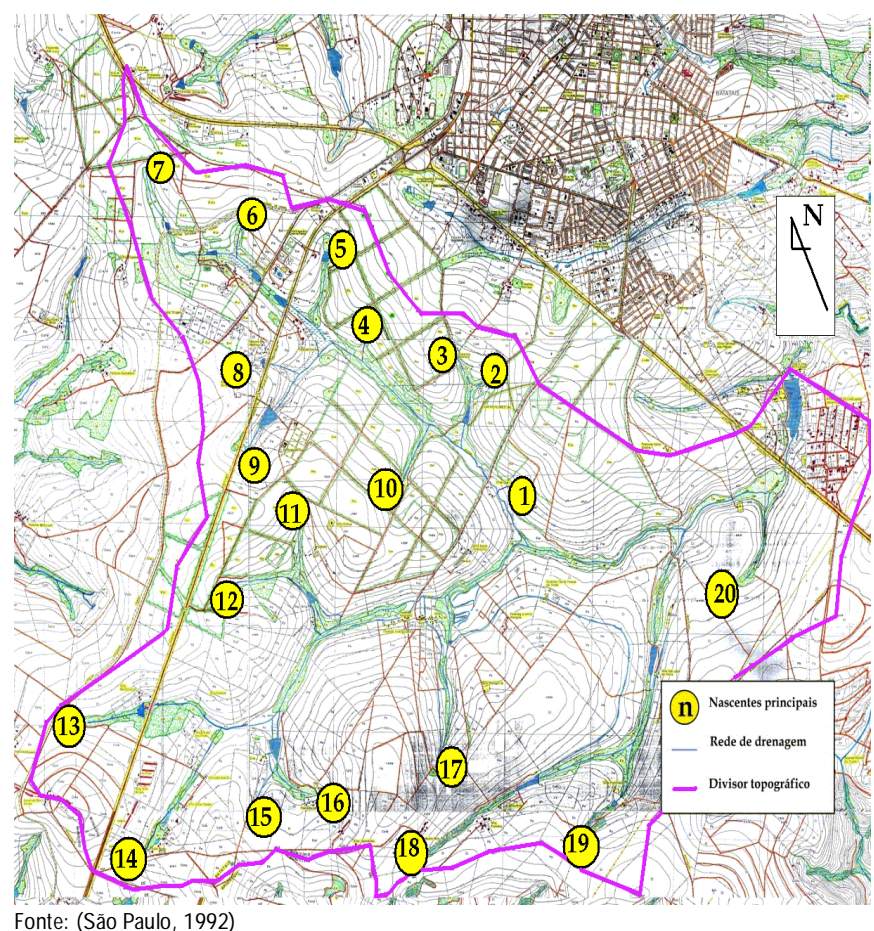

Figura 2. Microbacias avaliadas na Carta do Brasil Instituto G eográfico e Cartográfico (IGC), Escala 1:10000 
nascentes principais, número menor que o obtido para a escala do IBGE, deixando de representar as microbacias das nascentes 1, 4 e 15 da Figura 1. Por outro lado, a escala (maior) do IGC incrementa a rede de drenagem com os cursos d'água das nascentes 6,8 e 15 da Figura 2 . O produto final com a carta do IGC e a referência terrestre (Figura 2) mostra a inexistência de 1 microbacia (nascente 15 da Figura 1) e o aparecimento de outra microbacia de $1^{\mathrm{a}}$ ordem (nascente 15 da Figura 2) alterando, então, o número de microbacias de $1^{\mathrm{a}}$ ordem para $20 \mathrm{e}$ as de $2^{\mathrm{a}}$ ordem para 7 , sem alterar a hierarquia fluvial de $4^{\mathrm{a}}$ ordem da área de estudo mas com alterações sutis em suas características dimensionais.

O parâmetro que sofreu maior alteração na sua magnitude foi o comprimento da rede drenagem (Tabela 2), que passou de $33,71 \mathrm{~km}$ para $34,97 \mathrm{~km}$ entre as escalas 1:50000 e 1:10000 respectivamente, demonstrando a influência da escala na detecção dos tributários de $1^{\mathrm{a}}$ ordem e na aferição de suas dimensões.

A referência terrestre alcançou o valor de $35,54 \mathrm{~km}$ de comprimento, demonstrando que a aferição de campo melhora a nitidez das informações cartográficas. Estudando a evolução do modelado, Rodrigues et al. (2008) registraram redução do comprimento da rede de drenagem devida à ação antrópica.

O baixo valor do fator de forma $(0,45)$ define uma bacia mais alongada que circular, fato amparado pelo distanciamento do coeficiente de compacidade $(1,40)$ e do índice de circularidade $(0,50)$ da unidade. Cardoso et al. (2006), denotam que esse distanciamento da unidade indica menor tendência da microbacia ter a forma circular e menor susceptibilidade a enchentes.

Tonello et al. (2006), citam que a forma da microbacia é importante na determinação do tempo de concentração, ou seja, o tempo necessário para que toda a bacia contribua para sua saída após uma precipitação. Quanto maior o tempo de concentração menor a vazão máxima de enchente. Assim, considerando esse menor risco a enchentes acentuadas, a tendência é a de menor risco de assoreamentos dos cursos d'água e, consequentemente, da degradação ambiental da rede de drenagem.

O aumento no comprimento da rede de drenagem nas microbacias de $3^{\mathrm{a}}$ e $4^{\mathrm{a}}$ ordens e a diminuição nas microbacias de $1^{\mathrm{a}}$ e $2^{\mathrm{a}}$ ordens é devido à inserção de um novo canal nesta microbacia de $1^{\mathrm{a}}$ ordem, tornando-a uma microbacia de $2^{\mathrm{a}}$ ordem de grandeza, num ponto mais próximo à nascente, com área menor que a inicial.

A quantidade de tributários de $1^{\mathrm{a}}$ e $2^{\mathrm{a}}$ ordens na referência terrestre foi alterada e, com isso, a relação de bifurcação também. A redução na relação de bifurcação (de 3,6 para 2,86) e na relação do comprimento médio da rede de drenagem (de 4,20 para 3,31 ) entre as microbacias de $1^{\mathrm{a}}$ e $2^{\mathrm{a}}$ ordens (Tabela 3 ) é devida ao aumento de tributários de $2^{\mathrm{a}}$ ordem na mesma área da bacia. Rodrigues et al (2008) ressaltam que as condições de uso e a ocupação do solo da microbacia refletem o desenvolvimento agronômico e a preservação ambiental.

Segundo Cardoso et al. (2006), a densidade de drenagem é fator relevante na indicação do grau de desenvolvimento do sistema de drenagem de uma microbacia. Analisando as características do padrão de drenagem (Tabela 4), observa-se que a densidade de drenagem (Dd) é considerada baixa (Villela \& Mattos, 1975), assim como os valores da frequência de rios (F) e da razão de textura $(\mathrm{T})$, que indicam menor número de canais no terreno, com baixos valores de razão de bifurcação $(2,7)$.

Esses baixos valores da Dd, F e T geralmente estão associados a regiões de rochas permeáveis (Tonello et al., 2006), que facilitam a infiltração da água no solo, diminuindo o escoamento superficial e o risco de erosão e degradação ambiental. Rodrigues et al. (2008) citam que, quanto maiores esses valores mais intenso é o processo erosivo.

O valor médio da extensão de percurso superficial (caminho percorrido pelas águas pluviais) e do coeficiente de manutenção (área mínima para a existência de um canal) confirma a presença

Tabela 2. Características dimensionais da microbacia do Córrego da Cachoeira, Batatais, SP

\begin{tabular}{|c|c|c|c|c|c|c|}
\hline Características & IBGE & IGC & RT & Medias & DP & $\mathrm{CV}(\%)$ \\
\hline Área de drenagem $\left(\mathrm{km}^{2}\right)$ & 40,89 & 40,69 & 40,69 & 40,76 & 0,12 & 0,28 \\
\hline Perímetro (km) & 32,03 & 33,83 & 33,83 & 33,23 & 1,04 & 3,13 \\
\hline Comprimento $(\mathrm{km})>$ & 9,49 & 9,46 & 9,46 & 9,47 & 0,02 & 0,18 \\
\hline Largura $(\mathrm{km})>$ & 9,90 & 10,01 & 10,01 & 9,97 & 0,06 & 0,64 \\
\hline Comprimento total da rede de drenagem $(\mathrm{km})$ & 33,71 & 34,97 & 35,54 & 34,74 & 0,94 & 2,70 \\
\hline Comprimento médio da rede de drenagem $(\mathrm{m})$ & 1296,48 & 1344,89 & 1184,55 & 1275,31 & 82,24 & 6,45 \\
\hline Coeficiente de Compacidade & 1,40 & 1,48 & 1,48 & 1,45 & 0,05 & 3,18 \\
\hline Fator de forma & 0,45 & 0,46 & 0,46 & 0,46 & 0,01 & 1,26 \\
\hline Índice de Circularidade & 0,50 & 0,45 & 0,45 & 0,47 & 0,03 & 6,19 \\
\hline
\end{tabular}

IBGE - escala 1:50000; IGC - escala 1:10000; RT - referência terrestre; DP - desvio padrão; CV - coeficiente de variação

Tabela 3. Razão de bifurcação $(R b)$ e Relação do comprimento médio (RLm) entre cada ordem da microbacia do Córrego da Cachoeira, Batatais, SP

\begin{tabular}{|c|c|c|c|c|c|c|c|}
\hline Características & Escala & $1 / 2$ & $2 / 3$ & $3 / 4$ & Medias & DP & CV $(\%)$ \\
\hline Razão de bifurcação & $\begin{array}{l}\text { IBGE } \\
\text { IGC } \\
\text { RT }\end{array}$ & $\begin{array}{l}3,60 \\
3,60 \\
2,86\end{array}$ & $\begin{array}{l}2,50 \\
2,50 \\
3,50\end{array}$ & $\begin{array}{l}2,00 \\
2,00 \\
2,00\end{array}$ & $\begin{array}{l}2,70 \\
2,70 \\
2,79\end{array}$ & $\begin{array}{l}0,82 \\
0,82 \\
0,75\end{array}$ & $\begin{array}{l}30,32 \\
30,32 \\
27,01\end{array}$ \\
\hline Relação do comprimento médio & $\begin{array}{c}\text { IBGE } \\
\text { IGC } \\
\text { RT }\end{array}$ & $\begin{array}{l}4,20 \\
4,29 \\
3,31\end{array}$ & $\begin{array}{l}2,60 \\
2,60 \\
4,10\end{array}$ & $\begin{array}{l}2,89 \\
2,97 \\
2,94\end{array}$ & $\begin{array}{l}3,22 \\
3,27 \\
3,45\end{array}$ & $\begin{array}{l}0,86 \\
0,91 \\
0,59\end{array}$ & $\begin{array}{l}26,82 \\
27,77 \\
17,03\end{array}$ \\
\hline
\end{tabular}

IBGE - escala 1:50000; IGC - escala 1:10000; RT - referência terrestre; DP - desvio padrão; CV - coeficiente de variação 
Tabela 4. Padrão de drenagem da microbacia do Córrego da Cachoeira, Batatais, SP

\begin{tabular}{lcccrcr}
\hline \multicolumn{1}{c}{ Características } & IBGE & IGC & RT & Medias & DP & CV (\%) \\
Densidade de drenagem (Dd) & 0,82 & 0,86 & 0,87 & 0,85 & 0,03 & 3,11 \\
Frequência de rios (F) & 0,64 & 0,64 & 0,74 & 0,67 & 0,06 & 8,57 \\
Razão de textura (T) & 0,81 & 0,77 & 0,89 & 0,82 & 0,06 & 7,42 \\
Extensão de percurso superficial & 0,61 & 0,58 & 0,57 & 0,59 & 0,02 & 3,55 \\
Coeficiente de manutenção & 1213,10 & 1163,83 & 1145,18 & 1174,04 & 35,09 & 2,99 \\
\hline
\end{tabular}

IBGE - escala 1:50000; IGC - escala 1:10000; RT: referência terrestre; DP: desvio padrão; CV: coeficiente de variação

Tabela 5. Características do relevo da microbacia do Córrego da Cachoeira, Batatais, SP

\begin{tabular}{lccccrr}
\hline \multicolumn{1}{c}{ Características } & IBGE & IGC & RT & Medias & DP & CV (\%) \\
Maior Altitude (m) & 910,00 & 908,00 & 908,00 & 908,67 & 1,15 & 0,13 \\
Menor Altitude (m) & 782,00 & 800,00 & 800,00 & 794,00 & 10,39 & 1,31 \\
Amplitude Altimétrica (m) & 128,00 & 108,00 & 108,00 & 114,67 & 11,55 & 10,07 \\
Razão de relevo & 0,0135 & 0,0114 & 0,0114 & 0,0121 & 0,0012 & 10,02 \\
Razão de relevo relativo & 0,0040 & 0,0032 & 0,0032 & 0,0035 & 0,0005 & 13,32 \\
\hline
\end{tabular}

IBGE - escala 1:50000; IGC - escala 1:10000; RT: referência terrestre; DP: desvio padrão; CV: coeficiente de variação

de solos mais permeáveis na região de estudo. Santos \& Sobreira (2008), estudando regiões de baixa capacidade de infiltração de água obtiveram valores menores de $\mathrm{Cm}(178,2) \mathrm{e}$ Eps $(0,09)$ que a região em estudo, enquanto Pissarra et al. (2004) encontraram valores semelhantes de Eps e Cm para Latossolo Vermelho na região de Jaboticabal.

A razão de relevo estabelece a relação entre a diferença de altitudes máxima e mínima na bacia e o comprimento total do canal principal (Schumm, 1956). A baixa amplitude altimétrica (Tabela 5) resultou em baixos valores de razão de relevo e razão de relevo relativo, sugerindo uma microbacia com relevo relativamente suave $(1 \%)$ e propício para a agricultura.

\section{ConClusÕes}

1. O aumento da escala e da referência terrestre alterou o número de compartimentos hidrológicos e aumentou o comprimento da rede de drenagem, refletindo em alterações sutis nos parâmetros físicos analisados neste trabalho.

2. A referência terrestre complementa a informação da cartografia estudada com maior detalhamento sobre nascentes e córregos intermitentes.

3. A morfometria indica que a área tem relação positiva entre infiltração e deflúvio, com menor suscetibilidade á erosão e à degradação ambiental.

\section{LITERATURA CITADA}

Arraes, C. L.; Pissarra, T. C. T.; Rodrigues, F. M.; Zanata, M.; Campos, S. Morfometria dos compartimentos hidrológicos do município de Jaboticabal, SP. Revista Unopar Científica, Ciências Exatas e Tecnológicas, v.9, p.27-32, 2010a.

Arraes, C. L.; Rocha, A. M.; Moraes, R. A.; Pissarra, T. C. T.; Rodrigues, F. M.; Zanata, M. Estimativa da taxa de desmatamento do município de Bannach, Pará-Amazônia Legal, utilizando imagens Landsat5/TM. Revista de Ciências Agrárias, v.33, p.231-243, 2010b.
Brasil. Ministério do Planejamento e Coordenação Geral. Fundação Instituto Brasileiro de Geografia. Coleção Carta do Brasil. Departamento de Cartografia, Rio de Janeiro, Folha Batatais, SF-23-V-A-IV-4, Escala 1:50000, 1971.

Camargo, M. N. E.; Kaufmann, J. N. Sistema Brasileiro de Classificação de Solos. Boletim Informativo da Sociedade Brasileira de Ciência do Solo, v.12, p.11-13, 1987.

Candido, H. G.; Galbiatti, J. A.; Pissarra, T. C. T.; Martins Filho, M. V. Degradação ambiental da bacia hidrográfica do rio Uberaba: Uma abordagem metodológica. Engenharia Agrícola, v.30, p.179-192, 2010.

Cardoso, C. A.; Dias, H. C. T.; Soares, C. P. B.; Martins, S. V. Caracterização morfométrica da bacia hidrográfica do Rio Debossan, Nova Friburgo, RJ. Revista Árvore, v.30, p.241248, 2006.

Christofoletti, A. Geomorfologia. São Paulo: Blücher Universidade de São Paulo, 1974. 149p.

França, G. V. Interpretação fotográfica de bacias e de rede de drenagem aplicada a solos da região de Piracicaba, SP. Piracicaba: ESALQ/USP. 1968. 151p. Tese Doutorado

Horton, R. E. Erosional development of streams and their drainage basins: hydrophysical approach to quantitative morphology. Geological Society of America Bulletin, v.56, p.275-370, 1945 .

Lima Neto, R. T.; Mendonça, L. A. R.; Pereira J. A.; Sousa, C. A. V.; Gonçalves, J. Y. B.; Frischkorn, H. Análise morfométrica e ambiental da microbacia hidrográfica do rio Granjeiro, Crato/CE. Revista Escola de Minas, v.61, p.365-369, 2008.

Oliveira, P. T. S.; Alves Sobrinho, T; Steffen, J. L.; Rodrigues, D. B. B. Caracterização morfométrica de bacias hidrográficas através de dados SRTM. Revista Brasileira de Engenharia Agrícola e Ambiental, v.14, p.819-825, 2010.

Pissarra, T. C. T. (Coord). Informações básicas para o planejamento ambiental: Município de Jaboticabal. Jaboticabal: FUNEP, 2009. 70p.

Pissarra, T. C. T.; Politano, W.; Ferraudo, A. S. Avaliação de características morfométricas na relação solo-superfície da bacia hidrográfica do córrego Rico, Jaboticabal (SP). Revista Brasileira de Ciência do Solo, v.28, p.297-305, 2004. 
Politano, W.; Pissarra, T. C. T. Relações entre características morfométricas quantitativas e estimativa da vazão em função da área em microbacias hidrográficas de $2^{a}$ ordem de magnitude. Engenharia Agrícola, v.23, p.179-186, 2003.

Reis, L. C.; Reis, T. E. S.; Abi Saab, O. J. G. Caracterização da estrutura fundiária do município de Bandeirantes - PR, utilizando geoprocessamento. Engenharia Agrícola, v.28, p.345-354, 2008.

Rodrigues, F. M.; Pissarra, T. C. T.; Campo, S. Caracterização morfométrica da microbacia hidrográfica do córrego da fazenda Glória, município de Taquaritinga, SP. Irriga, v.13, p.310-322, 2008.

Rodrigues, V. A.; Carvalho, W. A. Morfometria da microbacia hidrográfica do córrego água limpa. IF Série Registros, v.39, p.15-25, 2009.

Santos, C. A.; Sobreira, F. G. Análise morfométrica como subsídio ao zoneamento territorial: o caso das bacias do Córrego Carioca, Córrego do Bação e Ribeirão Carioca na região do Alto Rio das Velhas - MG. Revista Escola de Minas, v.61, p.77-85, 2008.

São Paulo. Secretaria da Indústria, Comércio, Ciência e Tecnologia. Instituto de Pesquisas Tecnológicas do Estado de São Paulo - IPT. Mapa Geomorfológico do Estado de São Paulo. Boletim Técnico Científico, v.1, 1981.94p.

São Paulo. Secretaria de Planejamento e Gestão. Coordenadoria de Planejamento Regional. Instituto Geográfico e Cartográfico. Plano Cartográfico do Estado de São Paulo. São Paulo, SP, Escala 1:10000. 1992.
Schumm, S. A. Evolution of drainage systems and slopes in bedlands at Perth Amboy. Bulletin Geological Society America, v.67, p.597-646, 1956.

Silva, A. M.; Nalon, M.A.; Kronka, F. J. N.; Alvares, C. A.; Camargo, P. B.; Martinelli, L. A. Historical land cover/use in different slope and riparian buffer zones in watersheds of the State of SãoPaulo, Brazil. Scientia Agricola, v.64, p.325-335, 2007.

Smith, K. G. Standards for grading texture of erosional topography. American Journal Science, v.248, p.655-68, 1950.

Strahler, A. N. Dynamic basis of geomorphology. Bulletin Geological Society America, v.63, p.923-38, 1952.

Strahler, A. N. Quantitative analysis of watershed geomorphology. Transactions of American Geophysical Union, v.38, p.913-20, 1957.

Strahler, A. N. Dimensional analysis applied to fluvially eroded landforms. Bulletin Geological Society America, v.69, p.279$300,1958$.

Teodoro, W. L. I.; Teixeira, D.; Costa, D. J. L.; Fuller, B. B. O conceito de bacia hidrográfica e a importância da caracterização morfométrica para o entendimento da dinâmica ambiental local. Revista Uniara, v.20, p.137-156, 2007.

Tonello, K. C.; Dias, H. C. T.; Souza, A. L.; Ribeiro, C. A. A. S.; Leite, F. P. Morfometria da bacia hidrográfica da cachoeira das pombas, Guanhães - MG Revista Árvore, v.30, p.849-57, 2006.

Torres, J. L. R.; Silva, T. R.; Oliveira, F. G.; Araújo, G. S.; Fabian, A. J. Diagnóstico socioeconômico, ambiental e avaliação das características morfométricas da microbacia do Córrego Alegria em Uberaba-MG Sociedade \& Natureza, v.19, p.89-102, 2007.

Villela, S. M.; Matos, A. Hidrologia aplicada. São Paulo: McGraw-Hill do Brasil, 1975. 245p. 